\title{
A New Thermodynamic Parameter to Predict Formation of Solid Solution or Intermetallic Phases in High Entropy Alloys
}

O.N. Senkov*, D.B. Miracle

Air Force Research Laboratory, Materials and Manufacturing Directiorate, WrightPatterson AFB, Ohio 45433, USA

*Corresponding author, e-mail: oleg.senkov.ctr@us.af.mil

\begin{abstract}
A simple thermodynamic criterion is proposed to predict the presence or absence of equilibrium intermetallic phases in a high entropy alloy at a given temperature T. The criterion was verified using 45 currently available HEAs, for which equilibrium phases and respective annealing temperature are reported. The present model shows good correlation with experiment and gives an improved ability to predict formation of solid solution and intermetallic phases compared to earlier models.
\end{abstract}

Keywords: High entropy alloy; phase selection; equilibrium phases.

\section{INTRODUCTION}

Since the first reports of high entropy alloys (HEAs), a number of attempts have been made to predict phase formation in these alloys, in particular to predict compositions, which would favor formation of solid solution phases. The formation of disordered solid solution phases in HEAs was initially suggested to be governed by high entropy of mixing of alloying elements in these phases $[1,2]$ :

$$
\Delta \mathrm{S}_{\mathrm{mix}}=-\mathrm{R} \sum c_{i} \ln c_{i}
$$

Here $\mathrm{R}$ is the gas constant and $c_{i}$ is the atomic fraction of element $i$. Indeed, the high value of $\Delta \mathrm{S}_{\text {mix }}$ may reduce the Gibbs free energy, $\Delta \mathrm{G}_{\mathrm{mix}}$, of the solid solution (SS) below that of competing intermetallic (IM) phases. However, in spite of having high $\Delta \mathrm{S}_{\text {mix }}$ values, many HEAs are multi-phase and can also contain IM phases. For example, Otto et al. [3] studied the effects of entropy and enthalpy on phase formation in 5-component equimolar alloys. They started from a single-phase solid solution CoCrFeMnNi HEA [4] and made 5 other alloys by substituting $\mathrm{Co}, \mathrm{Cr}$, Fe or $\mathrm{Ni}$, one element at a time, with, respectively, Ti, Mo or V, 
$\mathrm{V}$ and $\mathrm{Cu}$. Although $\Delta \mathrm{S}_{\text {mix }}$ was the same, the modified alloys contained multiple SS and/or IM phases. Thermodynamic analysis showed that formation of multiple phases was consistent with minimization of the total Gibbs free energy, which includes both entropy and enthalpy contributions. It was concluded that $\Delta \mathrm{S}_{\text {mix }}$ stabilizes single-phase $\mathrm{SS}$ microstructures in rare cases. In many cases, the entropy effect is insufficient to counteract the driving forces that favor formation of secondary phases based on strongly interacting component pairs.

Several additional semi-empirical criteria for predicting solid solution phase formation in HEAs were introduced recently [5-9]. Similar to Hume-Rothery rules for binary substitutional solid solutions [10], these criteria focus on the differences of the atomic sizes $(\delta r)$, electronegativities $(\delta \chi)$, and valence electron concentrations (VEC) of the alloying elements. Additionally, the enthalpy of mixing $\left(\Delta \mathrm{H}_{\text {mix }}\right)$ and a parameter $\Omega$ were also used to develop criteria for the stability of SS, IM and/or amorphous phases in as-cast HEAs [11]. Zhang et al. [5] were the first who identified the importance of $\delta r$ and $\Delta \mathrm{H}_{\text {mix }}$ in the formation of SS, IM, SS+IM, or even amorphous phases, in as-cast HEAs. These parameters are calculated using the following equations:

$$
\begin{aligned}
& \delta r=\sqrt{\sum c_{i}\left(1-r_{i} / \bar{r}\right)^{2}} \cdot 100 \% \\
& \Delta H_{m i x}=\sum_{i<j} 4 H_{i j} c_{i} c_{j}
\end{aligned}
$$

Here $r_{i}$ and $c_{\mathrm{i}}$ are atomic radius and atomic fraction of element $i$; $\bar{r}=\sum c_{i} r_{i}$ is the average atomic radius; and $H_{i j}$ is an enthalpy of mixing of elements $i$ and $j$, which values are calculated by using Miedema's model as given in [12].

Statistical analysis of existing experimental data for HEAs produced by casting revealed that SS phases can be present if $\delta r<6.2 \%$ and $-12 \mathrm{~kJ} / \mathrm{mol}<\Delta \mathrm{H}_{\text {mix }}<5 \mathrm{kj} / \mathrm{mol}$, while IM phases can be present in HEAs for which $\delta r>3 \%$ and $\Delta \mathrm{H}_{\text {mix }}<0 \mathrm{~kJ} / \mathrm{mol}[5,13]$. HEAs with $\delta r>6.2 \%$ and $-40 \mathrm{~kJ} / \mathrm{mol}<\Delta \mathrm{H}_{\text {mix }}<-12 \mathrm{~kJ} / \mathrm{mol}$ can contain amorphous phases. The $\Delta \mathrm{H}_{\text {mix }}$ range for IM HEAs overlaps with the $\Delta \mathrm{H}_{\text {mix }}$ ranges for $\mathrm{SS}$ and amorphous HEAs. Therefore, the $\Delta \mathrm{H}_{\text {mix }}$ parameter cannot be used for the separation of SS and IM HEAs, but it can be used to predict whether SS or amorphous phase would form. Such selectivity of $\Delta \mathrm{H}_{\text {mix }}$ can be easily understood because $\Delta \mathrm{H}_{\text {mix }}$ is a characteristic of disordered phases, to which $\mathrm{SS}$ 
and amorphous phases belong, while the enthalpy of formation $\Delta \mathrm{H}_{\mathrm{IM}}$ should be used for IM phases, which is different from $\Delta \mathrm{H}_{\text {mix. }}$.

Trying to separate SS and IM phase fields, Yang and Zhang [6] proposed a parameter $\Omega$, which contains both $\Delta \mathrm{S}_{\text {mix }}$,and $\Delta \mathrm{H}_{\text {mix }}$, and is calculated as:

$\Omega=T_{m} \Delta S_{m i x} /\left|\Delta H_{m i x}\right|$

Here $T_{m}=\sum c_{i} T_{m i}$ and $T_{m i}$ is the melting point of element $i$. Only SS phases are found in ascast HEAs for which $\Omega \geq 1.1$ and $\delta r<3.6 \%$. SS and IM HEAs share the space of $3.6 \% \leq \delta r<$ $6.6 \%$ and $1.1 \leq \Omega \leq 10$, while at $\Omega>10$ only SS HEAs are identified. Most of the IM alloys have $\delta r \geq 6.6 \%$ and $1 \leq \Omega \leq 2$, and metallic glasses have $\delta r \geq 5 \%$ and $\Omega \leq 2$ [6].

These empirical criteria for phase selection were developed and tested using as-cast HEAs, which often contain non-equilibrium phases. Wang et al. [14] have recently evaluated these criteria to predict formation of equilibrium SS or IM phases in well homogenized and annealed HEAs. Using a limited number of data (27 alloys) available in the literature at that time, Wang et al. [14] found that the $\Delta \mathrm{H}_{\text {mix }}$ and $\delta \mathrm{r}$ ranges for HEAs with only SS phases after annealing narrowed significantly. Annealed HEAs with FCC and BCC solid solutions had $\Delta \mathrm{H}_{\text {mix }}>-7.5 \mathrm{~kJ} / \mathrm{mol}$ and $\delta \mathrm{r}<3.3 \%$, while as-cast SS HEAs had $\Delta \mathrm{H}_{\text {mix }}>-12.5 \mathrm{~kJ} / \mathrm{mol}$ and $\delta \mathrm{r}<$ $6.2 \%$. Annealed HEAs with intermetallic compounds appeared at $\Delta \mathrm{H}_{\text {mix }}<-7.5 \mathrm{~kJ} / \mathrm{mol}$ and $\delta \mathrm{r}$ $>3.3 \%$. However, three Al-containing HEAs that were identified as BCC structures had $\Delta \mathrm{H}_{\text {mix }}$ between -17 to $-10 \mathrm{~kJ} / \mathrm{mol}$ and $\delta \mathrm{r}$ between 5 to $6 \%$, which are typical for IM HEAs. They suggested that the Al-containing HEAs probably have a B2 phase. However, $\Delta \mathrm{H}_{\text {mix }}$ and $\delta \mathrm{r}$ are characteristics of the alloy composition only and are not affected by alloy processing. Therefore, narrowing the $\Delta \mathrm{H}_{\text {mix }}-\delta \mathrm{r}$ range for the SS HEAs after annealing may indicate that IM phases formed after annealing in other HEAs, which were solid solutions after casting, or this can just be due to much smaller number of the assessed alloys. While the effect of $\delta r$ on the formation of SS or IM phases can be understood from HumeRothery rules, the influence of $\Delta \mathrm{H}_{\text {mix }}$ and/or $\Omega$ values on the phase selection is not so clear. The authors who derived these criteria $[5,6,11,15]$ state that phase selection among different phases is determined by the competition between $\Delta \mathrm{H}_{\text {mix }}$ and $\mathrm{T} \Delta \mathrm{S}_{\text {mix. }}$. However this statement is thermodynamically incorrect, because these terms are not in competition, but rather work together to reduce the Gibbs free energy of the SS phase. 
Troparevsky et al. [16] (2015) proposed a model that, through the use of high-throughput computation of the enthalpies of formation of binary compounds, seemed to predict singlephase SS equiatomic HEAs. The stability of the competing SS and IM phases was analyzed by comparing the contributions to the Gibbs free energy from only mixing entropy ($\left.\mathrm{T} \Delta \mathrm{S}_{\mathrm{mix}}\right)$ for SS alloys and from only the enthalpy of formation $\left(\Delta H_{i j}^{I M}\right)$ for the ordered binary compounds. Thus they assumed that $\Delta \mathrm{H}_{\text {mix }}=0$ and $\Delta \mathrm{S}_{\mathrm{IM}}=0$, which is generally incorrect as $\Delta \mathrm{H}_{\text {mix }}$ can be very negative in some cases and $\Delta \mathrm{S}_{\text {Ім }}$ can be comparable with $\Delta \mathrm{S}_{\text {mix }}$ in ordered structures in which the number of alloying elements is higher than the number of sublattices. Troparevsky et al. also assumed that an HEA will have a single SS phase at a temperature $T$ if $\Delta H_{i j}^{I M}$ values for any binary system present in the alloy are above $-\mathrm{T} \Delta \mathrm{S}_{\text {mix. }}$. According to their model, among the currently developed non-refractory HEAs only those consisting of $\mathrm{Co}, \mathrm{Cr}, \mathrm{Fe}, \mathrm{Mn}$ and/or Ni are truly single-phase solid solutions, while other alloys should form multiple phases during annealing at $\mathrm{T}_{\mathrm{cr}}=0.55 \mathrm{~T}_{\mathrm{m}}$. The conclusion may be correct for equiatomic alloys, however, many non-equiatomic HEAs containing other elements than listed above also retain their single-phase SS structure after annealing (see Table 1). Using their approach, Troparevsky et al. provided a list of new HEAs, which should be single-phase solid solutions, to guide experimental searches. In addition to the combinations of 5 elements listed above, these alloys can also contain such elements as $\mathrm{Ir}, \mathrm{Os}, \mathrm{Rh}, \mathrm{Pd}, \mathrm{Ru}, \mathrm{Pt}$, - all are very expensive.

\section{A simple thermodynamic criterion for SS or IM phase formation}

In this paper we propose a new approach for the phase selection, which takes into account both enthalpy and entropy terms of the competing phases. The main assumption in this approach is that $\Delta \mathrm{H}_{\text {mix }}$ and $\Delta \mathrm{H}_{\mathrm{Im}}$ are related. Both terms can be calculated by summing bond energies between first-neighbor atom pairs and thus some relationship between these terms should exist. The entropy of formation, $\Delta \mathrm{S}_{\mathrm{IM}}$, of binary and/or ternary compounds is close to zero. However, it can be high in multi-component compounds that have more constituents than sublattices and/or have a large solubility range, although $\Delta \mathrm{S}_{\mathrm{IM}}$ should not be higher than $\Delta S_{\text {mix. }}$. For example, using the sublattice model for configurational entropy [17], it can be shown that $\Delta \mathrm{S}_{\mathrm{IM}}$ of $(\mathrm{A}, \mathrm{B})_{1}(\mathrm{C}, \mathrm{D}, \mathrm{E})_{3}$ compound is $0.997 \mathrm{R}$, where $\mathrm{R}$ is 
the gas constant. This is more than $60 \%$ of $\Delta \mathrm{S}_{\text {mix }}$ of a 5 -component equiatomic SS HEA. As the first approximation, we assume linear relationships between $\Delta \mathrm{H}_{\mathrm{IM}}$ and $\Delta \mathrm{H}_{\mathrm{mix}}$, and between $\Delta \mathrm{S}_{\mathrm{IM}}$ and $\Delta \mathrm{S}_{\mathrm{mix}}$ for HEAs with negative values of $\Delta \mathrm{H}_{\text {mix }}$ :

$\Delta \mathrm{H}_{\mathrm{IM}}=\kappa_{1} \cdot \Delta \mathrm{H}_{\text {mix }}$ and $\Delta \mathrm{S}_{\mathrm{IM}}=\kappa_{2} \cdot \Delta \mathrm{S}_{\mathrm{mix}}$

where $\kappa_{1}>1$ and $0 \leq \kappa_{2}<1$. The thermodynamic condition for the formation of a SS phase at a temperature T is:

$\Delta \mathrm{H}_{\text {mix }}-\mathrm{T} \Delta \mathrm{S}_{\text {mix }}<\Delta \mathrm{H}_{\mathrm{IM}}-\mathrm{T} \Delta \mathrm{S}_{\mathrm{IM}}$

Combining Eqs. (5) and (6) results:

$\kappa_{1}=\frac{\Delta H_{I M}}{\Delta H_{m i x}}<-\frac{T \Delta S_{m i x}}{\Delta H_{m i x}}\left(1-\kappa_{2}\right)+1 \equiv \kappa_{1}^{c r}(T)$

Equation (7) indicates that a SS phase with given $\Delta \mathrm{S}_{\text {mix }}$ and $\Delta \mathrm{H}_{\text {mix }}$ values $\left(\Delta \mathrm{H}_{\text {mix }}<0\right)$ is thermodynamically preferable at a temperature $\mathrm{T}$, if the $\Delta \mathrm{H}_{\mathrm{IM}} / \Delta \mathrm{H}_{\text {mix }}$ ratio (i.e. $\kappa_{1}$ ) for any competing IM phase is below the critical value $\kappa_{1}^{c r}(T)=\frac{T \Delta S_{m i x}}{\left|\Delta H_{m i x}\right|}\left(1-\kappa_{2}\right)+1$. It can be seen that $\kappa_{1}^{c r}$ increases with a decrease in $\left|\Delta \mathrm{H}_{\text {mix }}\right|$ and a decrease in the level of ordering of an intermetallic phase. Thus the condition for suppression of IM phases at a temperature $\mathrm{T}$ is:

$\kappa_{1}^{c r}(T)>\Delta \mathrm{H}_{\mathrm{IM}} / \Delta \mathrm{H}_{\text {mix }}$

Table 1 shows 45 HEAs, including 27 alloys analyzed by Wang et al. [14], for which information about phase contents in the annealed condition, as well as the annealing temperature, is available. We calculate $\delta r, \Delta \mathrm{H}_{\mathrm{mix}}, \Delta \mathrm{H}_{\mathrm{IM}}, \Omega\left(T_{A}\right), \kappa_{1}^{c r}\left(T_{m}\right)$ and $\kappa_{1}^{c r}\left(T_{A}\right)$ parameters for these alloys ( $\mathrm{T}_{\mathrm{A}}$ is the absolute annealing temperature) and compared how well these parameters can predict phases at a given annealing temperature. $\Delta \mathrm{H}_{\mathrm{IM}}$ values were calculated using equation similar to Eq. (3) and the enthalpy of formation values $\Delta H_{i j}^{I M}$ for binary intermetallics reported in [16]:

$\Delta H_{I M}=\sum_{i<j} 4 H_{i j}^{I M} c_{i} c_{j}$

$\kappa_{1}^{c r}$ was calculated for a partially ordered condition of an IM phase $\left(\kappa_{2}=0.6\right) . \Omega\left(T_{A}\right)$ was calculated using Eq. (4) in which $T_{A}$ was used instead of $T_{m}$. 
The $\Delta \mathrm{H}_{\text {mix }}-\delta r, \Omega\left(\mathrm{T}_{\mathrm{A}}\right)-\delta r$ and $\kappa_{1}^{c r}\left(T_{A}\right)-\Delta \mathrm{H}_{\mathrm{IM}} / \Delta \mathrm{H}_{\text {mix }}$ plots for the annealed alloys are shown in Figure 1 (a), (b) and (c), respectively. It can be seen that HEAs with the FCC crystal structures are well separated from IM HEAs with the use of $\Delta \mathrm{H}_{\text {mix }}$ and $\delta r$ parameters. Six out of seven of them fall within a top left rectangle (Figure 1a) identified by Wang et al. [14] $\left(-7.5<\Delta \mathrm{H}_{\text {mix }}<5 \mathrm{~kJ} / \mathrm{mol}, \delta r<3.3 \%\right)$ and one is slightly beyond of this rectangle (at $\Delta \mathrm{H}_{\text {mix }}=-$ $6.8 \mathrm{~kJ} / \mathrm{mol}$ and $\delta r=3.47 \%$ ). All alloys containing IM phases have $\Delta \mathrm{H}_{\text {mix }}<-6.8 \mathrm{~kJ} / \mathrm{mol}$ and $\delta r$ $>3.47 \%$. However SS HEAs consisting of BCC phases have $\Delta \mathrm{H}_{\text {mix }}$ and $\delta r$ values, which are common to both FCC and IM alloys. Thus $\left(\Delta \mathrm{H}_{\text {mix }}-\delta r\right)$ criterion does not work for HEAs containing BCC phases. The $\Omega$ criterion does not work at all (see Figure 1b): The analyzed SS and IM alloys fall in the same range of $\Omega$ and FCC HEAs are separated from all other alloys on the $\Omega\left(\mathrm{T}_{\mathrm{A}}\right)$ - $\delta r$ plot by atomic size difference only. This observation supports our statement that $\mathrm{T} \Delta \mathrm{S}_{\text {mix }}$ and $\Delta \mathrm{H}_{\text {mix }}$ terms from which $\Omega$ is derived are not competing with each other but represent the same state of a SS phase.

When $\kappa_{1}^{c r}\left(T_{A}\right)$ are plotted versus $\Delta \mathrm{H}_{\mathrm{IM}} / \Delta \mathrm{H}_{\text {mix }}$, clear separation of SS alloys from IM-containing alloys can be seen (Figure 1c). To visualize this, a dashed line corresponding to the condition $\kappa_{1}^{c r}\left(T_{A}\right)=\Delta \mathrm{H}_{\mathrm{IM}} / \Delta \mathrm{H}_{\text {mix }}$ is also shown in Figure 1c. Almost all SS alloys, except two with a BCC structure, fall above the dashed line ( $\kappa_{1}^{c r}\left(T_{A}\right)$ for SS alloys are above $\Delta \mathrm{H}_{\mathrm{IM}} / \Delta \mathrm{H}_{\text {mix }}$ ) and almost all IM-containing HEAs fall below this line $\left(\kappa_{1}^{c r}\left(T_{A}\right)\right.$ for these alloys are below $\left.\Delta \mathrm{H}_{\mathrm{IM}} / \Delta \mathrm{H}_{\text {mix }}\right)$. This analysis indicates that the $\kappa_{1}^{c r}$ parameter has an improved ability to predict the presence or absence of equilibrium IM phases in HEAs at a given annealing temperature than $\delta r, \Delta \mathrm{H}_{\text {mix }}$ and/or $\Omega$ parameters. However, the $\kappa_{1}^{c r}$ parameter cannot predict what types solid solution phases (FCC, BCC or HCP) will form. Other criteria should be used to estimate this.

\section{CONCLUSIONS}

A simple thermodynamic criterion ( $\kappa_{1}^{c r}(T)$ vs. $\Delta \mathrm{H}_{\mathrm{IM}} / \Delta \mathrm{H}_{\text {mix }}$ ) is proposed to predict what types of equilibrium phases (solid solutions or intermetallics) are present in a high entropy alloy at a given temperature $\mathrm{T}$. The criterion was verified using 45 currently available HEAs and showed good correlation with experiment. It is shown that the new criterion gives an improved ability to 
predict whether solid solution or intermetallic phases will form at a given temperature compared to earlier $\delta r v s \Delta \mathrm{H}_{\text {mix }}$ or $\delta r v s \Omega$ criteria.

\section{ACKNOWLEDGEMENTS}

Discussions with Dr. J.D. Miller and C. Woodward are much appreciated. Work by O.N. Senkov was supported through the U.S. Air Force on-site contract FA8650-10-D-5226 operated by UES, Inc., Dayton, Ohio. 
Table 1. Phases in several HEAs after annealing at a temperature $\mathrm{T}_{\mathrm{A}}$. Calculated parameters discussed in the paper are also shown.

\begin{tabular}{|c|c|c|c|c|c|c|c|c|}
\hline Material & $\begin{array}{l}\mathrm{T}_{\mathrm{A}}(\mathrm{K}) \\
\text { [refs.] }\end{array}$ & $\begin{array}{l}\text { Phases } \\
\text { at } T_{A}\end{array}$ & $\delta \mathrm{r}$ & $\begin{array}{c}\Delta \mathrm{H}_{\text {mix }} \\
(\mathrm{kJ} / \mathrm{mol})\end{array}$ & $\begin{array}{c}\Delta \mathrm{H}_{\mathrm{IM}} \\
(\mathrm{kJ} / \mathrm{mol})\end{array}$ & $\begin{array}{c}\Omega \\
\left(\mathrm{T}_{\mathrm{A}}\right)\end{array}$ & $\begin{array}{l}\kappa_{1}^{c r} \\
\left(\mathrm{~T}_{\mathrm{A}}\right)\end{array}$ & $\frac{\Delta H_{I M}}{\Delta H_{m i x}}$ \\
\hline $\mathrm{Al}_{0.25} \mathrm{CoCrFeNi}$ & $1273[18]$ & FCC & 3.15 & -6.78 & -14.19 & 2.39 & 1.95 & 2.09 \\
\hline $\mathrm{Al}_{0.3} \mathrm{CoCr}_{2} \mathrm{FeNi}$ & 973 [19] & $\mathrm{BCC}+\mathrm{FCC}+\sigma$ & 3.09 & -7.03 & -11.39 & 1.70 & 1.68 & 1.62 \\
\hline $\mathrm{Al}_{0.3} \mathrm{CoCrFeNi}$ & $1173[20]$ & $\mathrm{FCC}+\mathrm{B} 2$ & 3.33 & -7.30 & -15.76 & 2.06 & 1.82 & 2.16 \\
\hline $\mathrm{Al}_{0.3} \mathrm{CrFe}_{1.5} \mathrm{MnNi}_{0.5}$ & 973 [19] & $\mathrm{BCC}+\mathrm{FCC}+\sigma$ & 3.13 & -5.53 & -13.49 & 2.17 & 1.87 & 2.44 \\
\hline $\mathrm{Al}_{0.3} \mathrm{NbTa}_{0.8} \mathrm{Ti}_{1.4} \mathrm{~V}_{0.2} \mathrm{Zr}_{1.3}$ & $1473[21]$ & $\mathrm{BCC}$ & 4.80 & -6.34 & -5.62 & 2.42 & 1.97 & 0.89 \\
\hline $\mathrm{Al}_{0.3} \mathrm{NbTaTi}_{1.4} \mathrm{Zr}_{1.3}$ & $1473[21]$ & $\mathrm{BCC}+\mathrm{BCC}$ & 4.35 & -4.43 & -6.26 & 4.20 & 2.68 & 1.41 \\
\hline $\mathrm{Al}_{0.4} \mathrm{CoCrFeMnNiV}$ & 973 [19] & $\sigma$ & 3.54 & -11.96 & -22.56 & 1.29 & 1.52 & 1.89 \\
\hline $\mathrm{Al}_{0.4} \mathrm{Hf}_{0.6} \mathrm{NbTaTiZr}$ & $1473[22]$ & $\mathrm{BCC}$ & 4.25 & -9.04 & -9.25 & 1.92 & 1.77 & 1.02 \\
\hline $\mathrm{Al}_{0.5} \mathrm{CoCrCuFeNi}$ & 973 [23] & $\mathrm{BCC}+\mathrm{FCC}+\mathrm{IM}$ & 3.60 & -3.40 & -12.87 & 4.21 & 2.68 & 3.79 \\
\hline $\mathrm{Al}_{0.5} \mathrm{CrFeNiTiV}$ & 973 [19] & IMs & 4.77 & -19.85 & -35.52 & 0.59 & 1.24 & 1.79 \\
\hline $\mathrm{Al}_{0.5} \mathrm{CrMnFe}_{1.5} \mathrm{Ni}_{0.5}$ & 973 [19] & $\mathrm{BCC}+\sigma$ & 3.56 & -7.29 & -17.30 & 1.69 & 1.68 & 2.37 \\
\hline $\mathrm{Al}_{0.5} \mathrm{NbTa}_{0.8} \mathrm{Ti}_{1.5} \mathrm{~V}_{0.2} \mathrm{Zr}$ & $1473[21]$ & $\mathrm{BCC}+\mathrm{BCC}$ & 4.77 & -12.06 & -11.94 & 1.36 & 1.54 & 0.99 \\
\hline $\mathrm{Al}_{0.8} \mathrm{CrFe}_{1.5} \mathrm{MnNi}_{0.5}$ & 973 [19] & $\mathrm{BCC} / \mathrm{B} 2$ & 4.00 & -9.36 & -21.78 & 1.34 & 1.54 & 2.33 \\
\hline $\mathrm{Al}_{1.17} \mathrm{CoCrFeNi}$ & $973[18]$ & $\mathrm{BCC}+\mathrm{B} 2$ & 4.90 & -13.13 & -33.68 & 0.99 & 1.40 & 2.56 \\
\hline $\mathrm{Al}_{1.5} \mathrm{CrFe}_{1.5} \mathrm{MnNi}_{0.5}$ & $1273[19]$ & $\mathrm{BCC} / \mathrm{B} 2$ & 4.54 & -12.39 & -28.27 & 1.32 & 1.53 & 2.28 \\
\hline $\mathrm{Al}_{2} \mathrm{CoCrFeNi}$ & $973[18]$ & $\mathrm{BCC}+\mathrm{B} 2$ & 5.38 & -15.48 & -41.14 & 0.82 & 1.33 & 2.66 \\
\hline $\mathrm{AlCo}_{0.5} \mathrm{Cr}_{0.5} \mathrm{Fe}_{0.5} \mathrm{MnNiV}$ & 973 [19] & $\mathrm{BCC} / \mathrm{B} 2$ & 4.25 & -21.42 & -36.20 & 0.72 & 1.29 & 1.69 \\
\hline $\mathrm{AlCo}_{0.5} \mathrm{Cr}_{0.5} \mathrm{Fe}_{0.5} \mathrm{MnNiV}_{0.5}$ & 973 [19] & $\mathrm{BCC} / \mathrm{B} 2$ & 4.42 & -20.89 & -35.70 & 0.73 & 1.29 & 1.71 \\
\hline $\mathrm{AlCo}_{1.5} \mathrm{Cr}_{2} \mathrm{Fe}_{1.5} \mathrm{Mn}_{2} \mathrm{NiV}$ & 973 [19] & $\sigma$ & 3.76 & -11.74 & -22.88 & 1.31 & 1.52 & 1.95 \\
\hline $\mathrm{AlMo}_{0.5} \mathrm{NbTa}_{0.5} \mathrm{TiZr}$ & $1673[22]$ & $\mathrm{BCC}+\mathrm{BCC}$ & 4.76 & -23.76 & -25.96 & 0.84 & 1.33 & 1.09 \\
\hline $\mathrm{AlNb}_{1.5} \mathrm{Ta}_{0.5} \mathrm{Ti}_{1.5} \mathrm{Zr}_{0.5}$ & $1673[21]$ & $\mathrm{BCC}$ & 3.99 & -15.04 & -21.93 & 1.39 & 1.56 & 1.46 \\
\hline $\mathrm{Co}_{0.5} \mathrm{CrFeMn}_{1.5} \mathrm{Ni}$ & 973 [19] & $\mathrm{FCC}+\sigma$ & 2.29 & -4.03 & -7.89 & 3.12 & 2.25 & 1.96 \\
\hline $\mathrm{Co}_{1.5} \mathrm{Cr}_{0.5} \mathrm{FeMn}_{0.5} \mathrm{Ni}$ & 973 [19] & FCC & 2.08 & -3.49 & -6.26 & 3.53 & 2.41 & 1.80 \\
\hline $\mathrm{CoCr}_{0.75} \mathrm{FeMn}_{0.75} \mathrm{Ni}$ & 973 [19] & FCC & 2.23 & -4.08 & -6.83 & 3.17 & 2.27 & 1.68 \\
\hline $\mathrm{CoCr}_{1.25} \mathrm{FeMn}_{0.25} \mathrm{Ni}$ & 973 [19] & FCC & 1.98 & -4.13 & -5.43 & 2.97 & 2.19 & 1.31 \\
\hline $\mathrm{CoCr}_{2} \mathrm{FeNi}$ & 1273 [19] & FCC & 1.89 & -4.45 & -3.77 & 3.17 & 2.27 & 0.85 \\
\hline CoCrCuFeMn & $1123[3]$ & $\mathrm{FCC}+\mathrm{FCC}$ & 2.30 & 4.18 & 1.13 & 3.60 & 2.44 & 0.27 \\
\hline $\mathrm{CoCrFe}_{0.5} \mathrm{Mn}_{0.5} \mathrm{Ni}_{1.5}$ & 973 [19] & FCC & 2.11 & -4.89 & -6.23 & 2.52 & 2.01 & 1.27 \\
\hline $\mathrm{CoCrFeMnNi}$ & $1273[3]$ & FCC & 2.30 & -4.19 & -6.89 & 4.06 & 2.63 & 1.64 \\
\hline $\mathrm{CoCrFeNi}$ & $573[24]$ & FCC & 1.72 & -3.78 & -5.09 & 1.75 & 1.7 & 1.35 \\
\hline $\mathrm{CoCrFeNiTi}_{0.5}$ & 973 [25] & $\mathrm{FCC}+\mathrm{IM}$ & 4.12 & -11.59 & -19.37 & 1.10 & 1.44 & 1.67 \\
\hline CoCrMnNiV & 973 [3] & $\mathrm{FCC}+\mathrm{IM}$ & 2.87 & -9.18 & -17.18 & 1.42 & 1.57 & 1.87 \\
\hline CoFeMnMoNi & 973 [3] & $\mathrm{FCC}+\mathrm{IM}$ & 4.25 & -3.98 & -16.63 & 3.27 & 2.31 & 4.17 \\
\hline CoFeMnNiV & 973 [3] & $\mathrm{FCC}+\mathrm{IM}$ & 3.02 & -8.86 & -18.74 & 1.47 & 1.59 & 2.11 \\
\hline $\mathrm{CrFe}_{1.5} \mathrm{MnNi}_{0.5}$ & 973 [19] & $\mathrm{FCC}+\sigma$ & 2.02 & -2.13 & -6.12 & 5.03 & 3.01 & 2.88 \\
\hline CrFeMnNiTi & $973[3]$ & $\mathrm{BCC}+\mathrm{FCC}+\mathrm{IM}$ & 4.48 & -13.23 & -28.61 & 0.98 & 1.39 & 2.16 \\
\hline $\mathrm{CrMo}_{0.5} \mathrm{NbTa}_{0.5} \mathrm{TiZr}$ & $1473[26]$ & $\mathrm{BCC}+\mathrm{BCC}+\mathrm{IM}$ & 6.79 & -6.89 & -12.28 & 2.53 & 1.51 & 1.78 \\
\hline
\end{tabular}




\begin{tabular}{|l|c|c|c|c|c|c|c|c|}
\hline CrNbTiVZr & $1473[27]$ & BCC+IM & 7.17 & -4.70 & -9.17 & 4.19 & 1.84 & 1.95 \\
\hline CrNbTiZr & $1473[27]$ & BCC+IM & 7.13 & -5.25 & -12.37 & 3.23 & 1.65 & 2.36 \\
\hline $\mathrm{Cu}_{0.5} \mathrm{CoCrFeNi}$ & $1273[28]$ & FCC & 1.63 & 0.51 & -1.92 & 32.58 & 14.03 & -3.73 \\
\hline $\mathrm{HfNbTaTiZr}$ & $1473[29]$ & BCC & 3.93 & 2.66 & 2.36 & 7.42 & 3.97 & 0.89 \\
\hline $\mathrm{MoNbTaVW}$ & $1673[30]$ & BCC & 5.70 & -4.69 & -14.45 & 4.78 & 2.91 & 3.08 \\
\hline $\mathrm{MoNbTaW}^{\mathrm{NbTiV}}{ }_{2} \mathrm{Zr}$ & $1673[31]$ & BCC & 5.37 & -6.63 & -12.88 & 2.91 & 2.16 & 1.94 \\
\hline $\mathrm{NbTiVZr}$ & $1473[27]$ & BCC+BCC+BCC & 6.50 & -1.14 & 1.08 & 14.36 & 6.74 & -0.95 \\
\hline
\end{tabular}

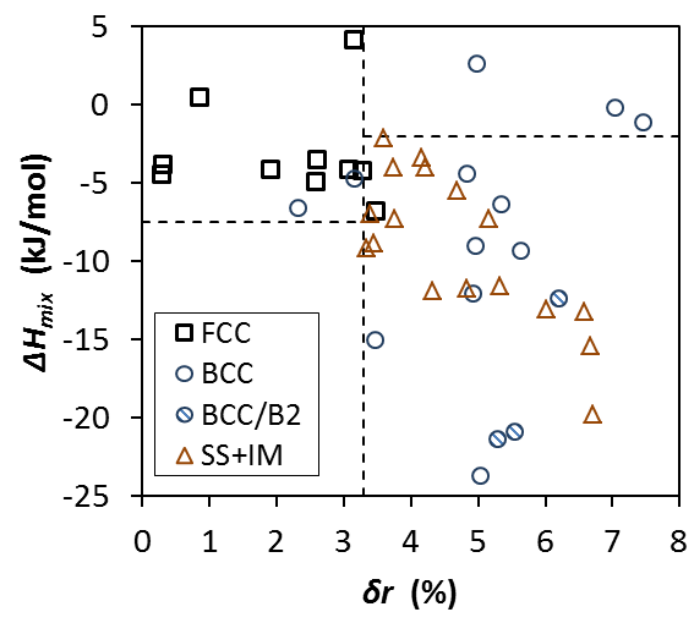

(a)

(b)
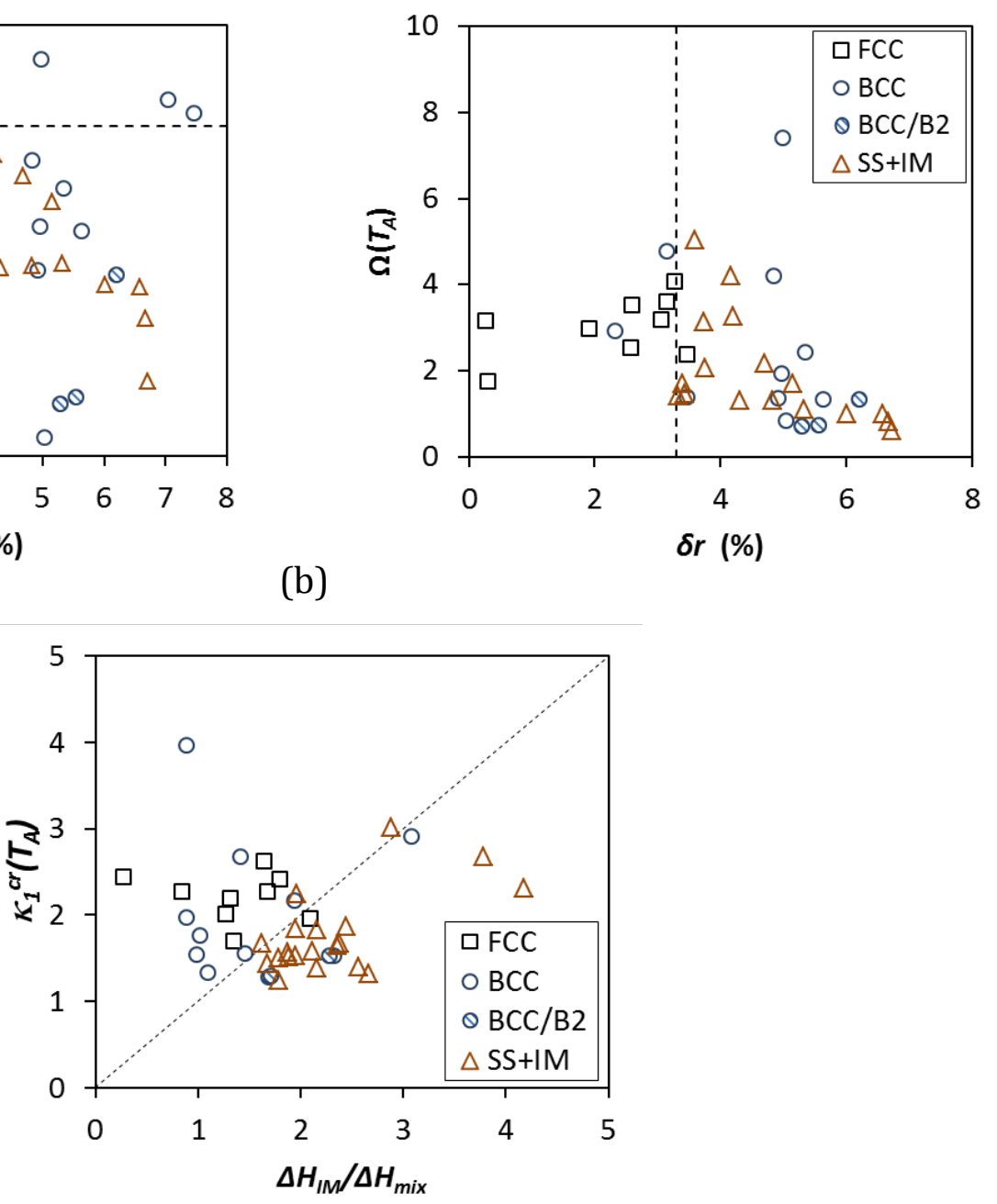

(c)

Figure 1. (a) The $\Delta \mathrm{H}_{\text {mix }}-\delta r$, (b) $\Omega\left(\mathrm{T}_{\mathrm{A}}\right)-\delta r$ and (c) $\kappa_{1}^{c r}\left(T_{A}\right)-\Delta \mathrm{H}_{\mathrm{IM}} / \Delta \mathrm{H}_{\text {mix }}$ plots for annealed HEAs with different phase contents after annealing. 


\section{REFERENCES}

[1] J.-W. Yeh, S.-K. Chen, S.-J. Lin, J.-Y. Gan, T.-S. Chin, T.-T.Shun, C.-H. Tsau, S.-Y. Chang, "Nanostructured high-entropy alloys with multiple principal elements: Novel alloy design concepts and outcomes," Adv. Eng. Mat., v 6, 2004, pp 299-303.

[2] J.-W. Yeh, S.-K. Chen, J.-Y. Gan, S.-J. Lin, T.-S. Chin, T.-T. Shun, C.-H. Tsau, S.-Y. Chang, "Formation of simple crystal structures in $\mathrm{Cu}-\mathrm{Co}-\mathrm{Ni}-\mathrm{Cr}-\mathrm{Al}-\mathrm{Fe}-\mathrm{Ti}-\mathrm{V}$ alloys with multiprincipal metallic elements," Metall. Mater. Trans. A, v 35 A, 2004, pp 2533-36.

[3] F. Otto, Y. Yang, H. Bei, E.P. George, "Relative effects of enthalpy and entropy on the phase stability of equiatomic high-entropy alloys," Acta mater., v 61, 2013, pp 2628-38.

[4] B. Cantor, I.T.H. Chang, P. Knight, A.J.B. Vincent, "Microstructural development in equiatomic multicomponent alloys," Mat. Sci. Eng. A, v 375-377, 2004, pp 213-18.

[5] Y. Zhang, Y.J. Zhou, J.P. Lin, G.L. Chen, P.K. Liaw, "Solid-solution phase formation rules for multi-component alloys," Adv. Eng. Mat., v 10, 2008, pp 534-38.

[6] X. Yang, Y. Zhang, "Prediction of high-entropy stabilized solid-solution in multi-component alloys," Mat. Chem. Phys., v 132, 2012, pp 233-38.

[7] S. Guo, C.T. Liu, "Phase stability in high entropy alloys: Formation of solid-solution phase or amorphous phase," Prog. Nat. Sci., v 21, 2011, pp 433-46.

[8] S. Guo, C. Ng, J. Lu, C.T. Liu, "Effect of valence electron concentration on stability of fcc or bcc phase in high entropy alloys," Journal of Applied Physics, v 109, 2011, pp.

[9] S. Guo, C.T. Liu, "Phase selection rules for complex multi-component alloys with equiatomic or close-to-equiatomic compositions," Chin. J. Nature, v 35, 2013, pp 85-96.

[10] W. Hume-Rothery, R.W. Smallman, C.W. Haworth, The Structure of Metals and Alloys, The Institute of Metals, London, 1969.

[11] S. Guo, "Phase selection rules for cast high entropy alloys: an overview," Materials Science and Technology, v 31, 2015, pp 1223-30.

[12] A. Takeuchi, A. Inoue, "Classification of Bulk Metallic Glasses by Atomic Size Difference, Heat of Mixing nad Period of Constituent Elements and Its Application to Characterization of the Main Alloying Element," Mater. Trans. JIM, v 46, 2005, pp 2817-29.

[13] G.A. Salishchev, M.A. Tikhonovsky, D.G. Shaysultanov, N.D. Stepanov, A.V. Kuznetsov, I.V. Kolodiy, A.S. Tortika, O.N. Senkov, "Effect of Mn and V on structure and mechanical properties of high-entropy alloys based on CoCrFeNi system," Journal of Alloys and Compounds, v 591, 2014, pp 11-24.

[14] Z. Wang, S. Guo, C.T. Liu, "Phase Selection in High-Entropy Alloys: From Nonequilibrium to Equilibrium," JOM, v 66, 2014, pp 1966-72.

[15] S. Guo, Q. Hu, C. Ng, C.T. Liu, "More than entropy in high-entropy alloys: Forming solid solutions or amorphous phase," Intermetallics, v 41, 2013, pp 96-103.

[16] M.C. Troparevsky, J.R. Morris, P.R.C. Kent, A.R. Lupini, G.M. Stocks, "Criteria for Predicting the Formation of Single-Phase High-Entropy Alloys," Physical Review X, v 5, 2015, pp 011041 (6 pp.).

[17] M. Hillert, Phase Equilibria, Phase Diagrams and Phase Transformations, 2nd Edition ed., Cambridge University Press, Cambridge, UK, 2007.

[18] Y.-F. Kao, T.-J. Chen, S.-K. Chen, J.-W. Yeh, "Microstructure and mechanical property of as-cast, -homogenized, and -deformed AlxCoCrFeNi $(0 \leq \mathrm{x} \leq 2)$ high-entropy alloys," J. Alloys Cmpounds, v 488, 2009, pp 57-64. 
[19] M.-H. Tsai, K.-Y. Tsai, C.-W. Tsai, C. Lee, C.-C. Juan, J.-W. Yeh, "Criterion for Sigma Phase Formation in Cr- and V-Containing High-Entropy Alloys," Mater. Res. Lett., v 1, 2013, pp 207-12.

[20] T.T. Shun, Y.C. Du, "Microstructure and tensile behaviors of FCC A10.3CoCrFeNi high entropy alloy," Journal of Alloys and Compounds, v 479, 2009, pp 157-60.

[21] O.N. Senkov, C. Woodward, D.B. Miracle, "Microstructure and Properties of AluminumContaining Refractory High-Entropy Alloys," JOM, v 66, 2014, pp 2030-42.

[22] O.N. Senkov, S.V. Senkova, C. Woodward, "Effect of aluminum on the microstructure and properties of two refractory high entropy alloys," Acta Materialia, v 68, 2014, pp 214-28.

[23] C. Ng, S. Guo, J.H. Luan, S.Q. Shi, C.T. Liu, "Entropy-driven phase stability and slow diffusion kinetics in an A10.5CoCrCuFeNi high entropy alloy," Intermetallics, v 31, 2012, pp $165-72$.

[24] Z. Wu, H. Bei, F. Otto, G.M. Pharr, E.P. George, "Recovery, recrystallization, grain growth and phase stability of a family of FCC-structured multi-component equiatomic solid solution alloys," Intermetallics, v 46, 2014, pp 131-40.

[25] L. Jiang, Y. Lu, Y. Dong, T. Wang, Z. Cao, T. Li, "Annealing effects on the microstructure and properties of bulk high-entropy CoCrFeNiTi0.5 alloy casting ingot," Intermetallics, v 44, 2014, pp 37-43.

[26] O.N. Senkov, C.F. Woodward, "Microstructure and properties of a refractory NbCrMo0.5Ta0.5TiZr alloy," Mater. Sci. Eng. A, v 529, 2011, pp 311-20.

[27] O.N. Senkov, S.V. Senkova, C. Woodward, D.B. Miracle, "Low-density, refractory multiprincipal element alloys of the $\mathrm{Cr}-\mathrm{Nb}-\mathrm{Ti}-\mathrm{V}-\mathrm{Zr}$ system: Microstructure and phase analysis," Acta mater., v 61, 2013, pp 1545-57.

[28] C.-M. Lin, H.-L. Tsai, H.-Y. Bor, "Effect of aging treatment on microstructure and properties of high-entropy $\mathrm{Cu} 0.5 \mathrm{CoCrFeNi}$ alloy," Intermetallics, v 18, 2010, pp 1244-50.

[29] O.N. Senkov, J.M. Scott, S.V. Senkova, D.B. Miracle, C.F. Woodward, "Microstructure and room temperature properties of a high-entropy TaNbHfZrTi alloy," J. Alloys Cmpds, v 509, 2011, pp 6043-48.

[30] O.N. Senkov, G.B. Wilks, D.B. Miracle, C.P. Chuang, P.K. Liaw, "Refractory high-entropy alloys," Intermetallics, v 18, 2010, pp 1758-65.

[31] O.N. Senkov, G.B. Wilks, J.M. Scott, D.B. Miracle, "Mechanical properties of

$\mathrm{Nb}_{25} \mathrm{Mo}_{25} \mathrm{Ta}_{25} \mathrm{~W}_{25}$ and $\mathrm{V}_{20} \mathrm{Nb}_{20} \mathrm{Mo}_{20} \mathrm{Ta}_{20} \mathrm{~W}_{20}$ refractory high entropy alloys," Intermetallics, $\mathrm{v} 19$, 2011, pp 698-706. 